\title{
SCIDiC
}

International Journal of Dentistry and Oral Science (IJDOS)

ISSN: 2377-8075

\section{Morphometric Study Of Parietal Foramen In South Indian Skulls}

Review Article

Edala Venkata Gana Karthik ${ }^{1}$, Thenmozhi ${ }^{2}$, Dhanraj Ganapathy ${ }^{3 *}$

${ }^{1}$ Graduate Student, Department of Prosthodontics, Saveetha Dental college and Hospitals, Saveetha Institute of medical and Technical Sciences, Saveetha University, Chennai, India.

${ }^{2}$ Professor and Head of Department of Anatomy, Saveetha Dental College and Hospitals, Saveetha Institute of Medical and Technical Sciences, Saveetha University, 162, Poonamallee High Road, Chennai - 600077, Tamil Nadu, India.

${ }^{3}$ Professor and Head of Department of Prosthodontics, Saveetha Dental College and Hospitals, Saveetha Institute of Medical and Technical Sciences, Saveetha University, 162, Poonamallee High Road, Chennai - 600077, Tamil Nadu, India.

\section{Abstract}

\begin{abstract}
A morphometric study of parietal foramen was done in South Indian dry human skulls.A total 40 dry human adult aged skull of unknown sex were studied. A 0-150 mm digital electronicalcalliper was used for Morphometric measurements. The results were tabulated using Microsoft Excel.Results were tabulated using Microsoft excel. Charts for various types of parietal foramen such a unilateral, bilateral, triple foramen, or absent parietal foramen were obtained.This article throws light on the importance of parietal foramen. It is considered important as it traverses the loose areolar tissue of the scalp by parietal emissary veins. And these veins being valve less, help in spread of infection quite easily into the intracranium.
\end{abstract}

Keywords: Parietal Foramen; Morphometries; Parietal Emissary Veins; Parietaliapermagna.

\section{Introduction}

The parietal bone foramina is usually minor. Two of them are located on either side of the sagittal suture which aresymmetrical, oval openings in the skull vault [1]. They are seen in the posterior aspect of the parietal bone and on Norma Occipitalis and Norma Verticalis.

They are separated from each other by a narrow bridge of bone. Obelion is a bony structure present over the sagittal suture medial to the parietal foramen [1]. The parietal foramina have sharply delineated margins and they do not have the surrounding sclerosis. Radiologist should be able to distinguish this foramen from the lytic lesions of the skull [2]. The parietal foramen is smaller than the burr hole of the neurosurgeon [2]. An emissary vein passes through it which connects the extracranial scalp veins with the superior sagittal dural venous sinus. Occasionally, a small branch of occipital artery passes through it. Its topography, size, number and shape is subjected to anatomical variations $[2,3]$.
The parietal foramen is considered important as it transmits a parietal emissary vein which traversed the loose areolar tissue which is considered as the dangerous area of the scalp. All the emissary foramens are considered important as they are the main channels of transmission of infections into the cranial cavity [4]. The parietal foramen may vary, sometimes being one on only one side, may be three, two, four on one side and one on the opposite side. [5].

Depending on the population studied the parietal foramen may be present on both sides between 43.2 and $62.7 \%$; between 22.2 and $62 \% ; 40 \%$. [5, 6]. The aim of the study was to evaluate the parietal foramen in dried adult skulls. Our research experience has prompted us in pursuing this study [7-16].

\section{Materials And Methods}

This study was done on 40 human dry skulls obtained from the Department of Anatomy, Saveetha Dental College, Chennai, Tamil Nadu. The crania which exhibited the pathological changes of

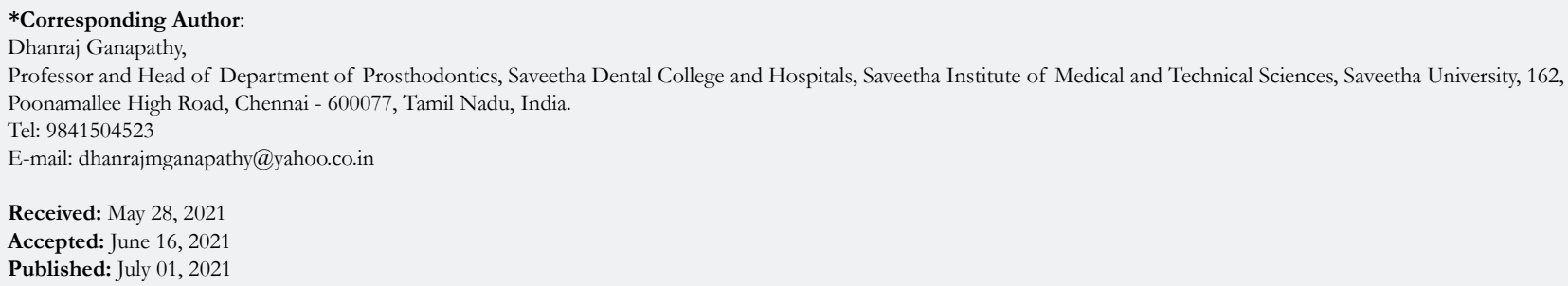

Copyright: Dhanraj Ganapathy ${ }^{\circ} 2021$. This is an open-access article distributed under the terms of the Creative Commons Attribution License, which permits unrestricted use, distribution and reproduction in any medium, provided the original author and source are credited. 
the skull cap were not included. They were not considered on the basis of race, age, sex. A0-150 mm digital electronic calliper was used to measure the morphometrics of parietal foramen from the parietal tuber and inter-parietal foramen distance. The results were obtained and were tabulated using Microsoft Excel.

\section{Results}

Enlarged parietal foramina is also called foramina Permagnaparitallia. The prevalence of enlarged foramina is in the range of 1 : 15,000 or 1: $25,000[6,17]$. There are only a few Indian studies done regarding the parietal emissary foramina. This was the stimulus to perform this present investigation from the anatomical specimens. The objectives of this article was to study the prevalence of the parietal emissary foramen and its morphometrics in adult South Indian population and to study their distance from the Parietal tube and the inter parietal foramen distance in case of two parietal foramen. This approach might be easier to locate the parietal foramen for neurosurgeons and dental surgeons.

The results shown in FIG.2.1 are the parietal foramen present only on the left side. The readings from the left parietal tuber are $8 \mathrm{~cm}$ for series $1,6.8 \mathrm{~cm}$ for series $2,7.8 \mathrm{~cm}$ for series $3,8.2 \mathrm{~cm}$ for series $4,7.7 \mathrm{~cm}$ for series 5 , and $7.9 \mathrm{~cm}$ for series 6 .
The results shown in FIG.2.2 are the parietal foramen present only on the right side. The readings from right parietal tuber are $6.3 \mathrm{~cm}$ for series $1,8.1 \mathrm{~cm}$ for series $2,8.3 \mathrm{~cm}$ for series $3,8.3 \mathrm{~cm}$ for series $4,7.9 \mathrm{~cm}$ for series $5,9.2 \mathrm{~cm}$ for series $6,8.9 \mathrm{~cm}$ for series $7,8.1 \mathrm{~cm}$ for series $8,9.5 \mathrm{~cm}$ for series $9,8.6 \mathrm{~cm}$ for series $10,7 \mathrm{~cm}$ for series $11,7.8 \mathrm{~cm}$ for series 12 .

The results shown in FIG.2.3 are the parietal foramen present on both the sides. The readings are shown as below.

The results in FIG.2.4 represents the presence of the parietal foramen in the subjects.

The results below is showing the presence of three foramen are shown in FIG.2.5

\section{Discussion}

The parietal bone develops in the 8 th week of intrauterine life from the intramembranous ossification $[2,6,17]$. The ossification centre is located near the parietal eminence and later it radiates towards the periphery in a sunburst pattern. The parietal bone ossification may vary and is essential to know about it to learn the

Figure 1. Represents prevalence the parietal foramen in 40 skulls.

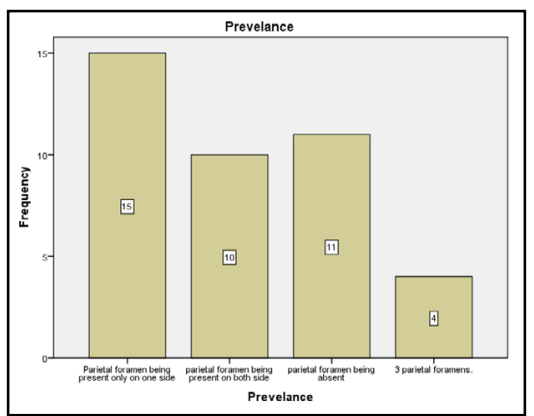

Figure 2.1. Represents the parietal foramen only on the left side.

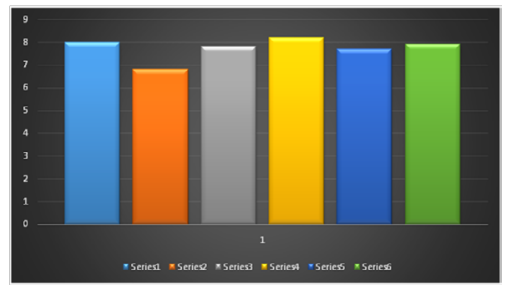

Figure 2.2. Represents parietal foramen present only on the right side.

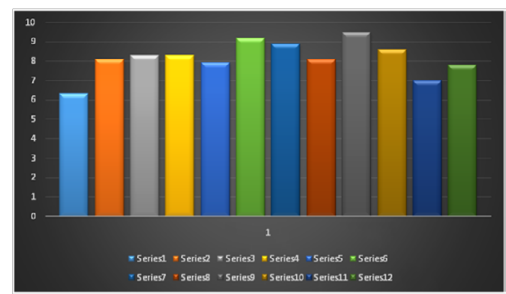

Figure 2.3. Parietal foramen present on both sides. Blue as left and orange as right parietal foramen respectively.

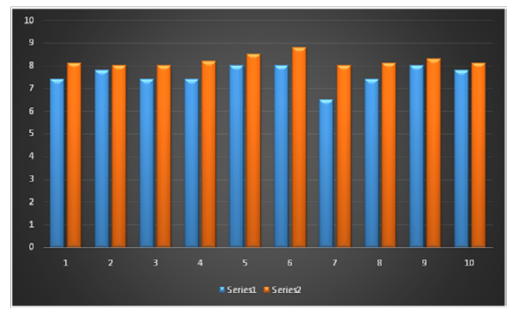


Figure.2.4 Results in $\mathrm{cm}$.

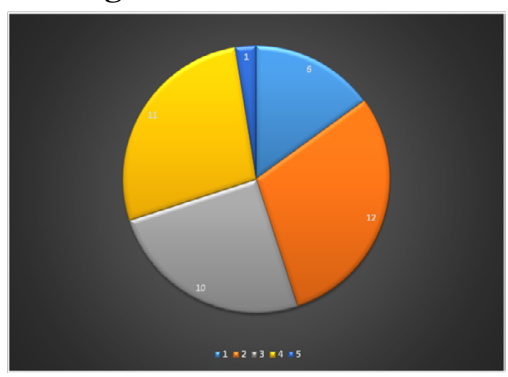

\begin{tabular}{|c|c|c|}
\hline From left parietal tuber & Between the parietal foramen & From right parietal tuber \\
\hline $7.4 \mathrm{~cm}$ & $1.5 \mathrm{~cm}$ & $8.1 \mathrm{~cm}$ \\
\hline $7.8 \mathrm{~cm}$ & $2.0 \mathrm{~cm}$ & $8.0 \mathrm{~cm}$ \\
\hline $7.4 \mathrm{~cm}$ & $0.9 \mathrm{~cm}$ & $8.0 \mathrm{~cm}$ \\
\hline $7.4 \mathrm{~cm}$ & $1.7 \mathrm{~cm}$ & $8.2 \mathrm{~cm}$ \\
\hline $8.0 \mathrm{~cm}$ & $0.4 \mathrm{~cm}$ & $8.5 \mathrm{~cm}$ \\
\hline $8.0 \mathrm{~cm}$ & $0.8 \mathrm{~cm}$ & $8.8 \mathrm{~cm}$ \\
\hline $6.5 \mathrm{~cm}$ & $1.5 \mathrm{~cm}$ & $8.0 \mathrm{~cm}$ \\
\hline $7.4 \mathrm{~cm}$ & $0.9 \mathrm{~cm}$ & $8.1 \mathrm{~cm}$ \\
\hline $8.0 \mathrm{~cm}$ & $1.3 \mathrm{~cm}$ & $8.3 \mathrm{~cm}$ \\
\hline $7.8 \mathrm{~cm}$ & $1.2 \mathrm{~cm}$ & $8.1 \mathrm{~cm}$ \\
\hline
\end{tabular}

Figure 2.5

\begin{tabular}{|c|c|c|c|}
\hline $\begin{array}{c}\text { Left Parietal } \\
\text { tuber distance }\end{array}$ & $\begin{array}{c}\text { Inter-parietal distance be- } \\
\text { tween middle and left PF }\end{array}$ & $\begin{array}{c}\text { Inter-parietal distance be- } \\
\text { tween middle and right PF }\end{array}$ & $\begin{array}{c}\text { Right Parietal } \\
\text { tuber distance }\end{array}$ \\
\hline $7.8 \mathrm{~cm}$ & $0.8 \mathrm{~cm}$ & $0.9 \mathrm{~cm}$ & $7.6 \mathrm{~cm}$ \\
\hline
\end{tabular}

Figure 3. Research carried out by various authors.

\begin{tabular}{|c|c|c|c|}
\hline Author & Unilateralforamen & Bilateralforamen & Absent foramen \\
\hline Yoshioka et al & $20 \%$ & $40 \%$ & $40 \%$ \\
\hline Boyd & $40.50 \%$ & $19.90 \%$ & $39.60 \%$ \\
\hline B. V. Murlimanju et al & $32.70 \%$ & $55.20 \%$ & $12.10 \%$ \\
\hline Present study & $42 \%$ & $25 \%$ & $30 \%$ \\
\hline
\end{tabular}

architecture of the sagittal suture near the obelion [2].

The formation of sagittal suture is achieved by the closure of 3 fontanelles. The third fontanelle is known as the sagittal fontanelle and is present in $50 \%-80 \%$ of cases, leading to the formation of unilateral or bilateral parietal foramina. It has been described that the third fontanelle usually closes within the first two years of life. The variations in the closure of the third fontanelle would lead to formation of accessory parietal emissary foramen, enlarged parietal foramen and the parietal fissure. $[2,18]$

The main function of the parietal foramen is transmitting the emissary vessels. These emissary veins being valve less is the main cause for the spread of infection. It is believed that the emissary foramina are typically a character of the humans, they are less frequent in lower animals and in some species they are absent. It has been reported that, there exists an important relationship between the emissary foramina and the diploic veins of the skull, which are involved in the spread of infection to the intracranium.[19]
The research carried out by various authors are given below In FIG.3

The clinical pathology associated with parietal foramen are is called parietaliapermagna. Foraminaparietaliapermagna or enlarged parietal foramina are a rare variant estimated to be less than 1 in 25,000 cases. These foramina have variable gross features like size, site, and number. It has a familial transmission due to heterozygous mutations of the homeobox of a totally useless rather an injurious character genes. This transmission is not only useless but also injurious in nature [20, 21].

\section{Conclusion}

This article puts light on the importance of parietal foramen. It is considered important as it traverses the loose areolar tissue of the scalp by parietal emissary veins. And these veins being valve less, help in spread of infection quite easily into theintracranium. The clinical pathology associated with parietal foramen is called parietaliapermagna being present in 1 in 25,000 cases. 


\section{References}

[1]. Currarino G. Normal variants and congenital anomalies in the region of the obelion. AJR Am J Roentgenol. 1976 Sep;127(3):487-94.Pubmed PMID: 183538.

[2]. Murlimanju BV, Saralaya VV, Somesh MS, Prabhu LV, Krishnamurthy A, Chettiar GK, et al. Morphology and topography of the parietal emissary foramina in South Indians: an anatomical study. Anat Cell Biol. 2015 Dec;48(4):292-8.Pubmed PMID: 26770881.

[3]. Boyd GI. The emissary foramina of the cranium in man and the anthropoids. J. Anat. 1930 Oct;65(Pt 1):108-21.

[4]. Jelev L, Malinova L. Occipital emissary foramina in human skulls: review of literature and proposal of a classification scheme of the occipital venous anastomoses in the posterior cranial fossa. Anatomy. 2020 Jan 1;14(1):11-5.

[5]. Berge JK, Bergman RA. Variations in size and in symmetry of foramina of the human skull. Clin Anat: The Official Journal of the American Association of Clinical Anatomists and the British Association of Clinical Anatomists. 2001 Nov;14(6):406-13.

[6]. McKinney AM. Skull base foramina: normal variations and developmental defects. In Atlas of Normal Imaging Variations of the Brain, Skull, and Craniocervical Vasculature 2017 769-813.

[7]. Hemalatha R, Dhanraj S. Disinfection of Dental Impression- A Current Overview. Cuddalore. 2016 Jul;8(7):661-4.

[8]. Ramya G, Pandurangan K, Ganapathy D. Correlation between anterior crowding and bruxism-related parafunctional habits. Drug invent. today. 2019 Oct $15 ; 12(10)$

[9]. Anjum AS, Ganapathy D, Kumar K. Knowledge of the awareness of dentists on the management of burn injuries on the face. Drug invent. today. 2019 Sep $1 ; 11(9)$.

[10]. Inchara R, Ganapathy D, Kumar PK. Preference of antibiotics in pediatric dentistry. Drug invent. today. 2019 Jun 15;11:1495-8.

[11]. Philip JM, Ganapathy DM, Ariga P. Comparative evaluation of tensile bond strength of a polyvinyl acetate-based resilient liner following various denture base surface pre-treatment methods and immersion in artificial salivary medium: An in vitro study. Contemp Clin Dent. 2012 Jul;3(3):298-301. Pubmed PMID: 23293485.

[12]. Gupta A, Dhanraj M, Sivagami G. Implant surface modification: review of literature. Internet J. Dent. Sci. 2009;7(1):10.

[13]. Indhulekha V, Ganapathy D, Jain AR. Knowledge and awareness on biomedical waste management among students of four dental colleges in Chennai, India. Drug invent. today. 2018 Dec 1;10(12):32-41.

[14]. Mohamed Usman JA, Ayappan A, Ganapathy D, Nasir NN. Oromaxillary prosthetic rehabilitation of a maxillectomy patient using a magnet retained two-piece hollow bulb definitive obturator; a clinical report. Case Rep Dent. 2013;2013:190180.Pubmed PMID: 23533823.

[15]. Ganapathy DM, Joseph S, Ariga P, Selvaraj A. Evaluation of the influence of blood glucose level on oral candidal colonization in complete denture wearers with Type-II Diabetes Mellitus: An in vivo Study. Dent Res J (Isfahan). 2013 Jan;10(1):87-92.Pubmed PMID: 23878569.

[16]. Menon A, Ganapathy DM, Mallikarjuna AV. Factors that influence the colour stability of composite resins. Drug invent. today. 2019 Mar 1;11(3).

[17]. Robinson RG. Congenital perforations of the skull in relation to the parietal bone. J Neurosurg. 1962 Feb 1;19(2):153-8

[18]. Mann RW, Manabe J, Byrd JE. Relationship of the Parietal Foramen and Complexity of the Human Sagittal Suture. Int J Morphol. 2009 Jun $1 ; 27(2): 553-64$.

[19]. Yoshioka N, Rhoton AL Jr, Abe H. Scalp to meningeal arterial anastomosis in the parietal foramen. Neurosurgery. 2006 Feb;58(1 Suppl):ONS123-6; discussion ONS123-6.Pubmed PMID: 16543869.

[20]. Tanriover N, Ulm AJ, Rhoton AL Jr, Kawashima M, Yoshioka N, Lewis SB. One-piece versus two-piece orbitozygomatic craniotomy: quantitative and qualitative considerations. Neurosurgery. 2006 Apr;58(4 Suppl 2):ONS229-37; discussion ONS-237.Pubmed PMID: 16582645.

[21]. Dharwal K. Foramina parietalia permagna: the ins and outs. Folia Morphol (Warsz). 2012 May;71(2):78-81.Pubmed PMID: 22648584. 